\title{
Ethnic Holidays as a Means of Formation of Ethnocultural Competence Among Schoolchildren
}

\author{
Natalya Spector ${ }^{1, a *}$ \\ 1 Moscow State University named after M. V. Lomonosov, 119899,1 Leninskiye Gory, Moscow, \\ Russia
}

\author{
aspektornata@gmail.com \\ ${ }^{*}$ Corresponding author
}

Keywords: holiday, ethnic holiday, intercultural education, ethnic values, ethnocultural competence, ethnocultural education, educational space

\begin{abstract}
One of the characteristic features of the beginning of the XXI century is the strengthening of the interaction and interdependence of countries and peoples in order to mutually enrich cultures. Under these conditions, the problem of tolerant coexistence of various ethnic and social communities is realized by scholars all over the world, since there are practically no mono-ethnic states. Consequently, the importance of multicultural education is emphasized, which allows a person to acquire an ability to have a tolerant attitude towards foreign culture experience. The experimental base was the 1621 school of the Central Administrative District of Moscow.
\end{abstract}

\section{Introduction}

Russia, being a multicultural society, is experiencing a need for a new world view aimed at integrating cultures and peoples with a view to their further rapprochement and spiritual enrichment. In this regard, the level of requirements of modern society to the school, creating a multicultural space, is rising. Strengthening the cultural status of education dictates the need for the training of pedagogical personnel capable of realizing its cultural orientation. The content of education as a pedagogically adapted social experience of mankind becomes a means of forming the competences necessary for the young generation, including ethnocultural competence.

\section{Methodology}

Formation of ethnocultural competence is understood by us as the process of an individual acquiring objective ideas, knowledge about ethnic groups and their cultures (including their own), skills, and practical experience in the field of interethnic interaction that promote mutual understanding and consolidation of various peoples.

However, in the modern education system there are contradictions between:

- The needs of society in the development of the cultural space of a multinational state and the insufficient elaboration of age-appropriate programs for programs, familiarization with the national traditions of a particular ethnic group and region;

- Awareness of the need for teachers to create pedagogical conditions for the formation of ethnocultural competence in the process of extracurricular activities, in particular children's holidays, and insufficient methodological preparedness of teachers.

Understanding the above contradictions allowed us to formulate the problem: the theoretical basis for the formation of children's ethnocultural competence in the process of preparing and conducting ethnocultural holidays.

Research object: the formation of ethnocultural competence of children in a secondary school with an ethnocultural component. children.

Research subject: the impact of children's parties on the formation of the ethnocultural competence of 
The purpose of the study is to determine conditions for the successful conduct of children's holidays that contribute to the formation of schoolchildren's ethnocultural competence as well as the ways to implement them in educational practice.

\section{Study}

It should be noted that school holidays play a special role in the formation of the ethnocultural competence of students. A holiday is a celebration day established in honor of or in the memory of someone, something. [8]. The main function of holidays is the sociocultural integration of one or another community of people. Different holidays carry out different types of integration. The main task of any holiday is the creation and maintenance of some joint rhythm.

This holiday can be compared to a plant. Its roots go back to the most ancient historical layers of human existence on earth, and its blooming summit reaches the sky of eternity. The holidays of different countries and nations have a lot in common, because all people are brothers. The holiday of every nation is full of originality, since the paths of people on the paths of history are different. From generation to generation, the holiday is preserved in culture as a jewel, because it is one of the most important conditions for the preservation of the viability of the people [9].

In these forms of work, students acquire experience in solving problems related to the peculiarities of interethnic interaction and aimed at the formation of ethnocultural competence.

Holidays, according to S. A. Shmakov, become a space and, at the same time, a universal way for students to self-fulfillment, meeting their needs for informal communication [7]. It is about creating a "safe space" that allows one to confidently and quietly exchange ideas, values, experiences, as a result of which the perception and understanding of the world around and each other changes, personal appeal increases. Thematic holidays, festivals, days of culture are considered as "components of intercultural education and training," which are necessary for understanding the phenomena in history, traditions of their own culture in comparison with traditions and cultures of other countries, preparing them for future life in the spirit of dialogue and cooperation.

The organization of the holiday is a creative and pedagogical process, where the totality of operations is grouped according to specific stages. Each stage, in turn, represents the sum of purposeful actions carried out in a certain sequence, which creates a system of pedagogical interaction between children and adults in the process of creating a holiday. Children's participation and preparation for holidays and events are carried out systematically and systematically, without disrupting the general rhythm of school life.

Ethnocultural education implies the development and acceptance by an individual of student's values, moral standards and moral norms, awareness of cultural belonging to the people, the representative of which he is and in whose environment he lives.

Ethnic holidays as a technology of ethnocultural education of schoolchildren, first of all, should contribute to the creation of such relationships between participants of the educational process, in which the goal is achieved, familiarization of those educated with ethnic values.

Ethnic values are a set of life attitudes, orientations, ideals, meanings, cultural traditions that members of the ethnic group themselves consider the most characteristic and important for their people and, ultimately, for the purpose of man in general [9].

1. For younger schoolchildren, taking into account the psychological and pedagogical features of this age, it is possible to form the foundations of ethnoculture through the formation of a person's emotional-axiological attitude to a small homeland, to its history and culture; and through active and positive participation in preserving the best of what has been accumulated by previous generations.

2. The pedagogical potential (of people's games / traditions / holidays) consists in the multifunctional significance and universality of this type of activity, which aims to recreate and assimilate people's social experience, in which children's ideas expand, emotional-value attitudes are formed, and personality behavior is developed and improved. 
Primary schoolchildren can educate the foundations of ethnoculture, taking into account the psychological and pedagogical features of the development of children of primary school age:

- Active development of cognitive interest in the phenomena of life around;

- An ability to absorb a large amount of systematic knowledge about the world;

- Unity of emotional and cognitive processes;

- Fostering patriotic feelings based on emotional experiences in creative (play) activities;

- Reflection of the accumulated knowledge about the world in independent activities.

The idea of preserving and reproducing ethnocultural values is a system-forming element of holidays as an educational technology.

The educational significance of children's holidays depends entirely on the quality of their content and on the level of organization and hosting. A teacher needs to know characteristics of children's age and the interests of the developing personality, determine the form of the celebration (matinee, festival, competition, evening, concert, performance, theatrical performance, etc.).

In the course of the experimental work at the school No. 1621, we held a number of holidays aimed at the formation of ethnocultural competence. For example, we held "Family holidays of different nations" with the $5^{\text {th }}$ grade students. This contributed to familiarizing children with the traditions of family holidays of different nations, raising tolerance and respect for their own peers, other people, and other ethnic groups.

With the $6^{\text {th }}$ grade students, the event "Seasons in tradition and music" was organized, during which the connection of music with the Jewish people and other nations' traditions of the world was revealed. These events contributed to the formation of ethnocultural competence not only among students, but also among all other participants.

The school held major holidays not only of the Russian calendar, but also of the Jewish one, including such national holidays as "Sukkot", "Rosh Hashanah", "Purim", "Pesach", and others. In the organization and holding of these events, children's personal interest, activities, and motivation were significantly growing not only towards each other but also towards other cultures and traditions. It can be said that within the framework of these holidays, conditions were created for the children to realize their place in the world, create their own holistic picture, and active life position on a number of personal questions.

We can find proof in the students' essays:

I. Yu. ( $5^{\text {th }}$ grade student): “... I think that we do not need to think about how to be ourselves. We just need to live in this life honestly and in good faith. Do not be mean, do not deceive people. Honestly do your job ...”.

E. S. ( $5^{\text {th }}$ grade student): “... Personally for me to be myself is to follow my own rules, just to live as I feel, but not to offend the people around me ...".

M. V. ( $8^{\text {th }}$ grade student): “... Hanukkah is a celebration of light. But this is not just lamps and torches, this is the light of our souls. I believe that this light should be given not only in Hanukkah, but also every day, every hour ...".

V. Sh. (10 ${ }^{\text {th }}$ grade student): “... First of all, I am a Jew and I must remain in spite of everything, I must honor my traditions, culture, the memory of my ancestors ...".

According to the results of the preparation and holding of the holiday, a collection of teaching materials was prepared for teachers on how to organize such an even in a school ("Hanukkah as a symbol of loyalty to itself').

One of the successful events was the "Tu-bi-Shvat" holiday ("New Year of the Trees"). The goal of the project was to develop students' interest in environmental issues and feelings of caring for the environment. Within the event, semantic blocks were proposed, each of them was an important part of the whole and included various activities: preparing presentations for students and protecting projects, performing tasks for integrated lessons, conducting an interactive exhibition, and so on. 
An interactive exhibition was held with the aim of raising the level of age integration of children. Students of three grades (7-9) presented their work for students of lower grades. A total of 7 stations were presented to the attention of schoolchildren by the number of plants for which the land of Israel was (and still is) famous. At each station, students received new information through presentations, films, fairy tales, or music. After each event, a survey was conducted to establish feedback. Feedback from teachers and students indicates that they were satisfied by their active participation in the project.

I. S. (a social pedagogue): "Many thanks to the organizers, teachers, and participants of the funeducational theater stations project. The variety of contests, prizes, and tasty treats pleasantly surprised. Children and teachers were delighted. It was difficult to get schoolchildren away from one station to another one, as they were very passionate about games, contests, and overwhelmed with impressions. More such exciting activities!".

L. P. (a history teacher): "The interactive exhibition was great interest among both students and teachers. Visibility in learning plays an important role. The game form of learning allows one to uncover students' abilities, to gain additional knowledge about the Tu bi Shvat. The fascinating form has caused a lively response from schoolchildren". "I really enjoyed "traveling" around the Tu bi Shvat. Of all the stations, the Olivki station, where we planted plants together, was the most memorable".

E.S. (a student, 2A class): "I liked the station "Vinohrad," where we played games and guessed riddles."

M.P. (a student, 4A class): "I really liked the touching story "The generous tree." The tree gave everything to the boy, because he loved him very much, just like our parents love and care for us".

In these forms of work, students acquire experience in solving problems related to the peculiarities of interethnic interaction and aimed at the formation of ethnocultural competence.

\section{Conclusion}

State requirements for education are aimed at finding new ways to update the content and forms of children's holiday programs, as a means of forming ethno-cultural competences, as well as children's abilities. All of these introduces them to the process of joint activities with peers and adults to universal values, building a basis for personal culture, aesthetic norms, the formation of the $21^{\text {st }}$ century civilian qualities. All this requires a serious understanding of scientists, specialists, and practicing teachers.

Own experience of organizing and conducting children's holidays shows that the teachers of additional education need special professional training. They should have special knowledge related to the preparation and holding of holidays, constantly expanding this knowledge, combining traditional methods and innovative achievements. This approach was used by us in the course of experimental work at the School No. 1621 with an ethnocultural (Jewish) component.

A number of holidays have caused emotional responses from students and teachers and contributed to the formation of ethnocultural competence. All of the above leads to the following observation: children's holidays are the important components in a comprehensive school. Every holiday is a unique pedagogical phenomenon, the most important element of any education system, part of an integral educational process, a form of collective unity (teachers, children, and their parents). Such important components ("pedagogy holiday - children - creativity") exist in a single complex. During holidaya, all kinds of activities and knowledge are merged together, where children's personalities have the opportunity to show an attitude towards themselves and the reality.

\section{References}

[1] Afanasyeva, A. B. (2011). Actualization of ethnocultural education in the multicultural environment of the modern school. News of the Russian State Pedagogical University named after A. I. Herzen, 142, pp. 134-143.

[2] Vedeneev, G. A. (2008). Mass Russian holidays: The state and development trends: Study Guide. Volgograd, Russia. 
[3] Volkov, G. N. (1999). Ethnopedagogy: a textbook for students of environments and higher pedagogical educational institutions. Moscow, Russia: Publishing Center “Academy”.

[4] Lebedeva, O. A. (2008). School holidays and their role in the development of children. Rehabilitation. Education. Development. St. Petersburg, Russia.

[5] Goikhman, O. Ya. (2010). Organizing and conducting events: a tutorial. Moscow, Russia: Publisher INFRA - M.

[6] Poshtareva, T. V. (2005). Pedagogical conditions of the formation of ethnocultural competence and tolerance of children. Stavropol, Russia: SKIPKRO.

[7] Abulkhanova, K. A., Vasina, M. V., Lapteva, L. G., \& Slastenina, V. A. (1998). Psychology and pedagogy. Moscow, Russia: Sovershenstvo.

[8] Ozhegov, S. I., \& Shvedova, N. Yu. (1999). Explanatory Dictionary of the Russian language (4th edition). Moscow, Russia: Russian Academy of Sciences, Institute of the Russian Language named after V. V. Vinogradov.

[9] Frolov, A. S. (1997). Pedagogical interaction of children and adults in organizing children's parties. Moscow, Russia.

[10] Chernyy, G. P. (1990). Pedagogical technology of a mass holiday. Moscow, USSR: Molodaya gvardiya.

[11] Suleimanyan, A. G. (Ed.) (2008). Ethnopsychology and Ethnopedagogy: A reader. Moscow, Russia.

[12] Rosemary Henze, (2002). Leading for diversity: How school leaders promote positive interethnic relations. New York, NY: Corwin Press.

[13] Yedovizky, M. (2001). Teaching to speak, learning to listen: Hebrew education for Russian-speakers in the FSU and Israel. Jerusalem, Israel.

[14] Zykova, N. V. (n.d.). The educational potential of children holidays. Retrieved from http://nsportal.ru/shkola/dopolnitelnoe-obrazovanie/library/statya-vospitatelnyi-potentsial-detskikhprazdnikov Н.В.Зыкова/. 